\title{
A CLINICAL STUDY TO CORRELATE THE FACIAL FORM AND MAXILLARY CENTRAL INCISOR TOOTH FORM IN MALES AND FEMALES OF DAVANGERE POPULATION
}

\author{
Deepak Bansal ${ }^{1}$, Shruti Sharma ${ }^{2}$, Manjit Kumar ${ }^{3}$, Amrit Khosla $^{4}$ \\ ${ }^{1}$ Professor, Department of Prosthodontics, Bhojia Dental College and Hospital, Himachal Pradesh, India \\ ${ }^{2}$ Professor, Department of Oral medicine, Daswani Dental College, Rajasthan, India \\ ${ }^{3}$ Professor and Head of Department, Department of Prosthodontics, Bhojia Dental College and Hospital, Himachal Pradesh, India \\ ${ }^{4}$ Professor, Department of Prosthodontics, Bhojia Dental college and Hospital, Himachal Pradesh, India
}

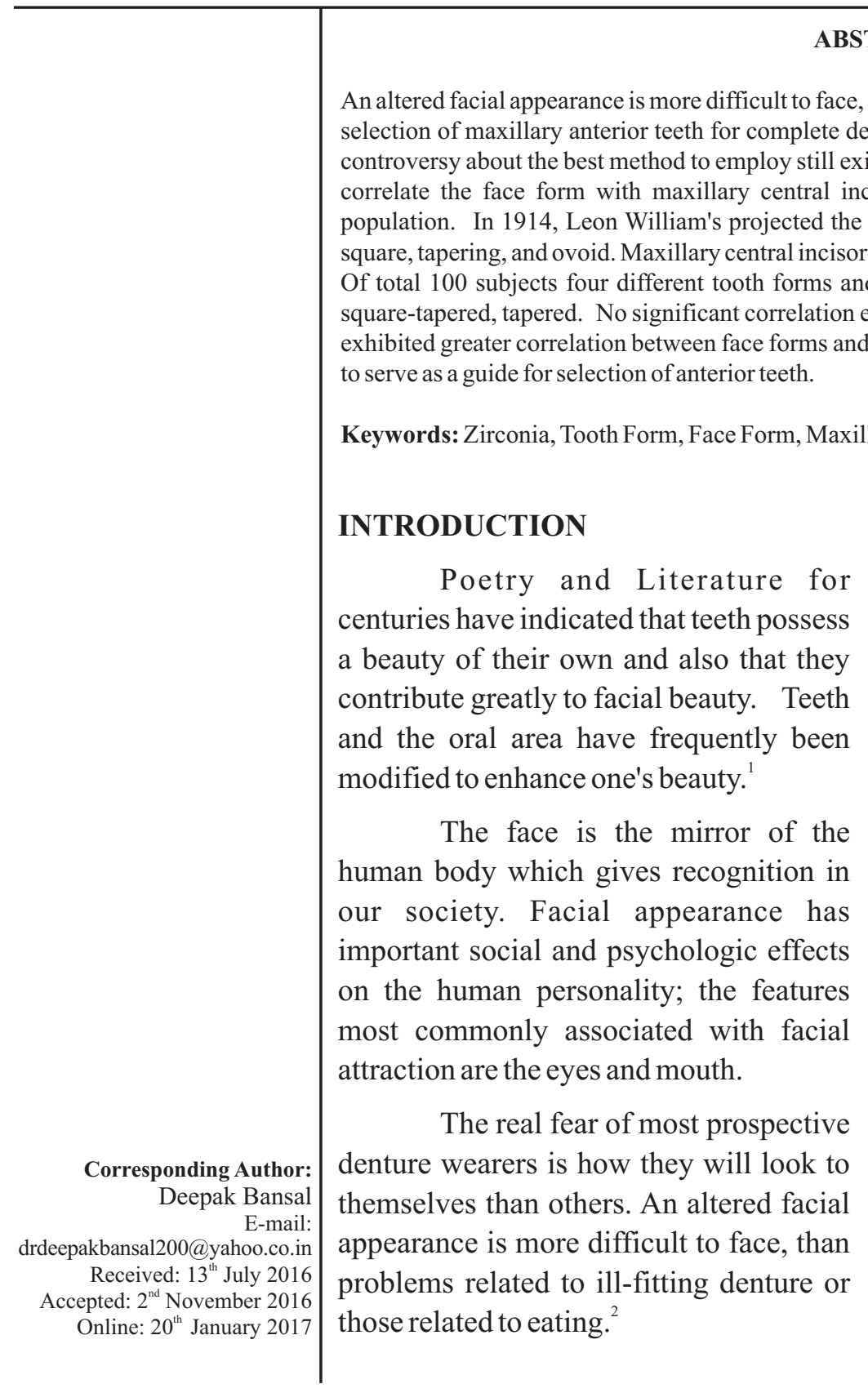

BSTRACT

An altered facial appearance is more difficult to face, than problems related to ill-fitting denture or eating. The selection of maxillary anterior teeth for complete denture has long posed problem in clinical practice and a controversy about the best method to employ still exists. An attempt is made in the present study to clinically

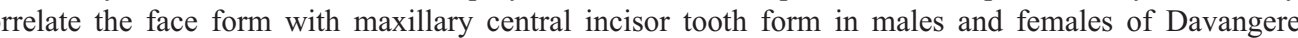
the "the form method" where he classified facial forms as exhibited greater correlation between face forms and inverted tooth form but that correlation is not sufficient Keywords: Zirconia, Tooth Form, Face Form, Maxillary Central Incisor

\section{INTRODUCTION}

centuries have indicated that teeth possess a beauty of their own and also that they contribute greatly to facial beauty. Teeth and the oral area have frequently been modified to enhance one's beauty. human body which gives recognition in our society. Facial appearance has ond psychologic effects (a) most commonly associated with facia

The real fear of most prospective 
and a controversy about the best method to employ still exists. ${ }^{5}$

Several methods are of questionable validity, as no universally accepted method for selection of teeth has yet been established. ${ }^{5}$

A review of literature shows that several factors and numerous methods have been devised for the evaluation of reliable esthetic factors in determining artificial form with little or no validity.

To update Leon William's classification of tooth forms and face forms is the only accepted theory regarding selection of maxillary central incisor tooth form in relation to face form. Several theories and methods were devised for the last 100 years for selection of artificial teeth in relation to one or the other orofacial landmarks. Some of the theories that were devised are: ${ }^{6}$

\section{Concept of "Correspondence and harmony":}

$>$ Typal form concept

$>$ Temperamental technic

$>$ Berry's biometric ratio method

$>$ Clapp's "Tabular dimension table" method

$>$ Valderama's "Molar tooth basics"

$>$ Cigrande technique

$>$ Williams' "Typal form method"

$>$ "Mold guide sample teeth"

$>$ "Wavrin Instrumental Guide" Technique

> "Maxillary Arch Outline Form"

$>$ Wright's Photometric method"

$>$ Multiple Choice Method"

$>$ Stein's Co-ordinated size technique"

$>$ "Anthropometric-Cephalic Index Method"

$>$ "Bioform Technic"

> "Selection Indicator instrument method"

$>$ "House instrument method"

> "Automatic Instant Selector Guide"

As no universally accepted method for selection of teeth has yet been established, dentists must seek guidance from a variety of techniques using their clinical experience and esthetic sense to attain what is hoped will be an acceptable result.
In 1914, Leon Williams ${ }^{6}$ projected the "Typal form method" where he classified facial forms as square, tapering, and ovoid and maxillary central incisors were selected according to the facial forms. Later based on Berry's Biometric ratio method and Williams' Typal method in 1926, Warwin developed the instrumental guide. Dentsply company developed a similar guide, to find out the facial form called as "Trubyte tooth indicator" which is being utilized in this study.

There has been lots of correlation studies done between face profile, ridge, arch and other bony orofacial landmarks of an individual but, few studies have been reported regarding relation between tooth and face form.

Hence, an attempt is made in the present study to clinically correlate the face form with maxillary central incisor tooth form in males and females of Davangere population.

\section{AIMS \& OBJECTIVES:}

1. To determine the predominant tooth form in males of Davangere population.

2. To determine the predominant tooth form in females of Davangere population.

3. To determine the predominant face form in males of Davangere population.

4. To determine the predominant face form in females of Davangere population.

5. To determine the correlation between tooth form and face form in males and females of Davangere population.

\section{MATERIAL \& METHOD}

Armamentarium: (Figure 1, Figure 2)

1. Alginate (Kromopan Tamilnadu)

2. Stock Trays (Perforated Aticomedical Ambala)

3. Dental Stone (Neelkanth Jodhpur)

4. Base Formers (Sheetal Nashik)

5. Dental Plaster(Kalabai Mumbai)

6. Pencil

7. Dividers

8. Scale

9. Digital Vernier Calipers (Blue star Ambala) 


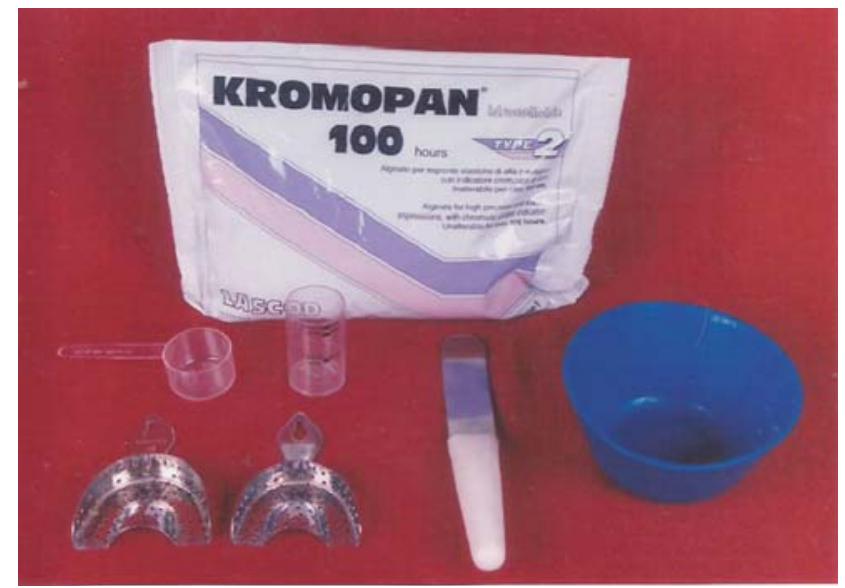

Figure 1: Materials used in the study

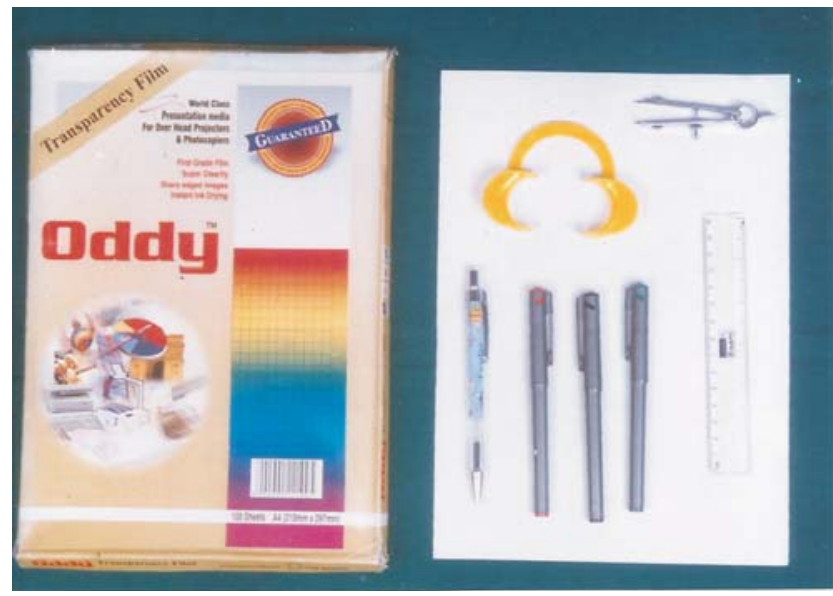

Figure 2: Armamentarium used in the study

10. Trubyte Tooth Indicator(dentsply/ York Div York $\mathrm{Pa})$

11. OHP Sheets

12. OHP Markers

The Following criteria were used in selection of samples:

1. Subjects involved in the study did not have any congenital or acquired orofacial and dental anomalies.

2. The subjects had a full complement of natural teeth.

3. There was no history of previous restorative or orthodontic treatment on the anterior teeth.

4. There was a regular alignment of anterior teeth without any overlapping and any form of imbrications.

5. Teeth with intact contact points and without any spacing.

6. Subjects with rotated teeth, peg shaped teeth and any morphologically malformed teeth were not included in the study.

7. Absence of stains, calculus and deposits which would interfere with the measurements.

8. Maxillary central incisor teeth without fractures, cracks or chipping.

9. Subjects with healthy periodontium were taken.

10. Subjects having a history of facial trauma in surgery being performed in the maxillo-facial region were not included in the study.

The samples thus selected for this investigation represents an excellent cross section of Davangere population, in that the subjects were young adults belonging to different age groups.

\section{Description about Trubyte Tooth Indicator (Figure 3)}

Trubyte tooth indicator instrument (dentsply/ York Div York Pa) is a valuable guide in selecting the proper tooth form and size of anterior teeth. It is designed for easy reading as 16:1 ratio between facial dimensions and anterior tooth, as researchers have shown that this ratio to be the average relationship between the size of the face and maxillary central incisors in natural dentition.

The facial outline was determined by the outcome of the temporal bone at the height of hairline, temporal

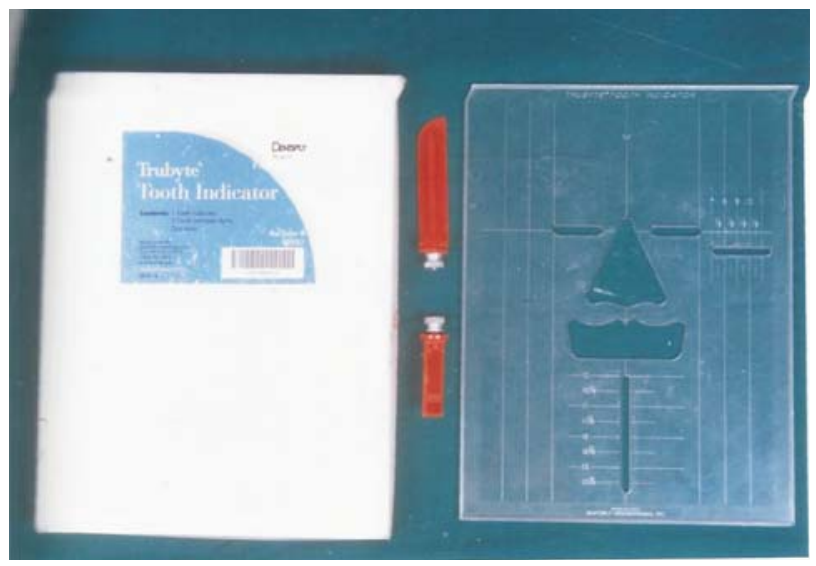

Figure 3: Densply Trubite indicator 
process of zygomatic arch and gonion. These reference anatomical marks (bitemporal, bizygomatic and bigonion) are marked on an OHP sheet which is designed in the same fashion as that of trubyte indicator with vertical line on both sides (Figure 4).

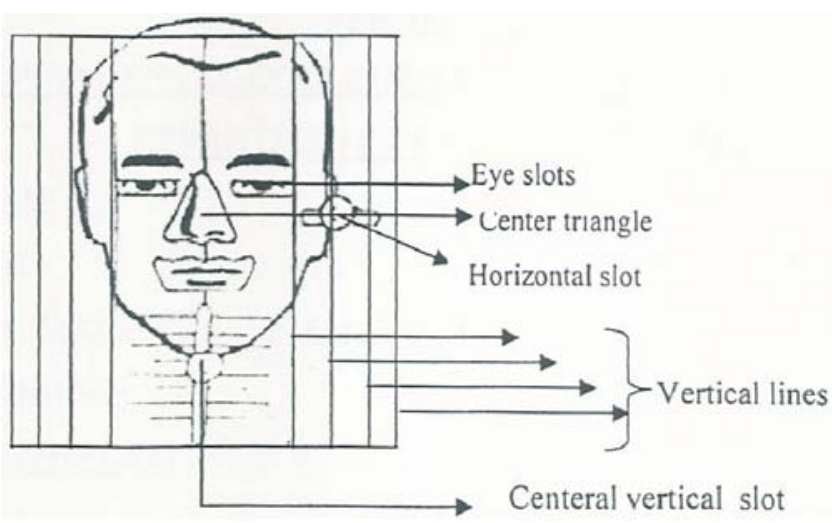

Figure 4: Showing placement of Trubite indicator on patient's face

\section{Clinical Determination of Tooth Form}

For Clinical determination of tooth form, the subjects were made to sit upright in a dental chair and maxillary impression were made with irreversible hydrocolloid material by using properly selected stock trays. Dental stone was manipulated according to ADA specification and impressions were poured by vibrating gently to remove air bubbles and base was made with dental plaster. Later, the casts were checked for accuracy.

Then, the length was measured from the free gingival margin at the deeper portion of the free marginal gingival i.e. centre of the tooth to the incisal edge.

The total cervico-incisal length of the right maxillary central incisor was measured and based on that length the tooth was divided into three equal halves. Now, we are having a tooth divided into three equal halves i.e. incisal third, middle third and cervical third.

The width was measured from medial to distal contact points on the cast belonging to each subject in the study by means of digital caliper (Figure 5). These measurements were correlated to classify them into different typal forms.

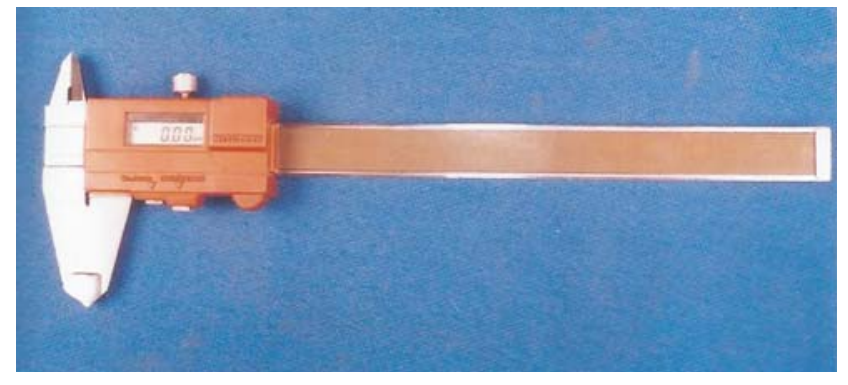

Figure 5: Digital Vernier caliper

- A square incisor was one that was parallel measially and distally for whole of its cervicoincisal length.

- A tapered incisor was one that converged from the incisal edge to the cervix.

- An ovoid incisor was one that was biconvex.

- A square tapered incisor was one that was parallel mesially and distally for atleast half of the cervicoincisal length and then converged to the cervix.

\section{RESULT}

The present study was aimed to find out the correlation between the face form and maxillary central incisor tooth forms in male and female population of Davangere of different age groups between 18 to 26 years. To correlate the results obtained for ideal positioning and replacement of maxillary central incisor in a complete denture or partial denture construction respectively.

Face form and tooth form was taken as the basic criteria for selection of subjects. Accordingly 50 male and 50 female subjects were selected and their face form and tooth forms were evaluated clinically.

Subjects of Davangere origin who fulfilled the required criteria were chosen and impressions were made to obtain casts for measuring the mesio-distal width and cervico-incisal length of maxillary central incisor and also face form was traced on an OHP sheet using a Trubyte Tooth Indicator (Figure 6).

The results thus obtained were tabulated and statistically compared. The statistical analysis was done by Chi-Square test and Kappa measure of agreement. 
The statistical comparison was a qualitative analysis of the two factors i.e. the face form and tooth form. The concordance of the clinical observations were studied using the qualitative analysis.

The clinically obtained face forms and tooth forms were correlated statistically.

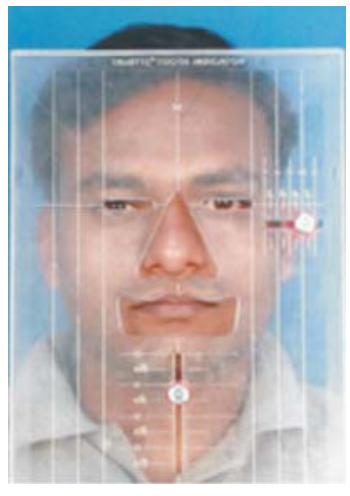

Figure 6: Placing Trubite indicator on subject's face
The results were as follows:

Of total 100 subjects, four different tooth forms and face forms were evaluated. The four different tooth forms and face forms that were evaluated are (Figure. 7);

1) Square

2) Ovoid

3) Square-tapered

4) Tapered

Table 1 shows 53 ovoid, 14 square, 23 square tapered and 10 tapered tooth forms and also shows 25 ovoid, 21 square-tapered, 7 tapered and 0 square forms out of total 100 subjects (Graph I). When they were correlated, Table I shows 53 ovoid tooth forms were correlating with 25 ovoid, 0 square, 21 square tapered, and 7 tapered face forms i.e. ovoid tooth forms are

Table 1: Correlation between tooth form and face form

\begin{tabular}{|c|c|c|c|c|c|}
\hline & No. & $\begin{array}{c}\text { Ovoid } \\
\mathbf{n}(\%)\end{array}$ & $\begin{array}{c}\text { Square } \\
\mathbf{n}(\%)\end{array}$ & $\begin{array}{c}\text { Square- } \\
\text { Tapered }\end{array}$ & Tapered \\
\hline Ovoid & 53 & $\begin{array}{c}25 \\
(47.2 \%)\end{array}$ & - & $\begin{array}{c}21 \\
(39.6 \%)\end{array}$ & $\begin{array}{c}7 \\
(13.2 \%)\end{array}$ \\
\hline Square & 14 & $\begin{array}{c}05 \\
(35.7 \%)\end{array}$ & $\begin{array}{c}1 \\
(2.1 \%)\end{array}$ & $\begin{array}{c}6 \\
(42.9 \%)\end{array}$ & $\begin{array}{c}2 \\
(14.3 \%)\end{array}$ \\
\hline $\begin{array}{c}\text { Square- } \\
\text { Tapered }\end{array}$ & 23 & $\begin{array}{c}06 \\
(26 \%)\end{array}$ & $\begin{array}{c}1 \\
(4.3 \%)\end{array}$ & $\begin{array}{c}6 \\
(26 \%)\end{array}$ & $\begin{array}{c}10 \\
(43 \%)\end{array}$ \\
\hline Tapered & 10 & $\begin{array}{c}03 \\
(30 \%)\end{array}$ & - & $\begin{array}{c}3 \\
(30 \%)\end{array}$ & $\begin{array}{c}4 \\
(40 \%)\end{array}$ \\
\hline Total & 100 & $\begin{array}{c}39 \\
(39 \%)\end{array}$ & $\begin{array}{c}2 \\
(2 \%)\end{array}$ & $\begin{array}{c}36 \\
(36 \%)\end{array}$ & $\begin{array}{c}23 \\
(23 \%)\end{array}$ \\
\hline
\end{tabular}

$\mathrm{X}^{2}=15.1$

$\mathrm{P}=0.09 \mathrm{NS}$

Face form ${ }^{\mathrm{OC}}$ Tooth form

Ovid $\rightarrow 25 / 39 \rightarrow 64 \%$

Square $\rightarrow 1 / 2 \rightarrow 50 \%$

Square tapered $\rightarrow 6 / 36 \rightarrow 17 \%$

Tapered $\rightarrow 4 / 23 \rightarrow 17 \%$

Overall agreement $=36 \% \quad$ Kappa $=0.46$

Fair agreement between tooth form and face form

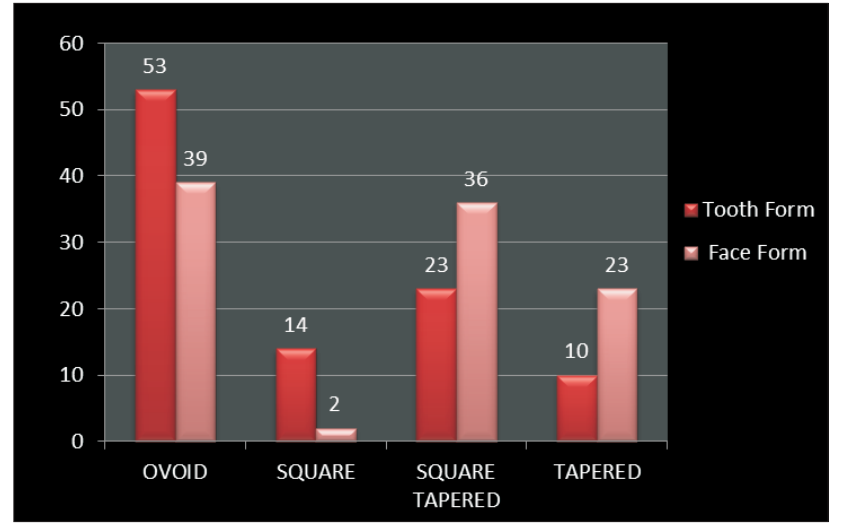

Graph I : Relationship between Tooth Form \& Face Form

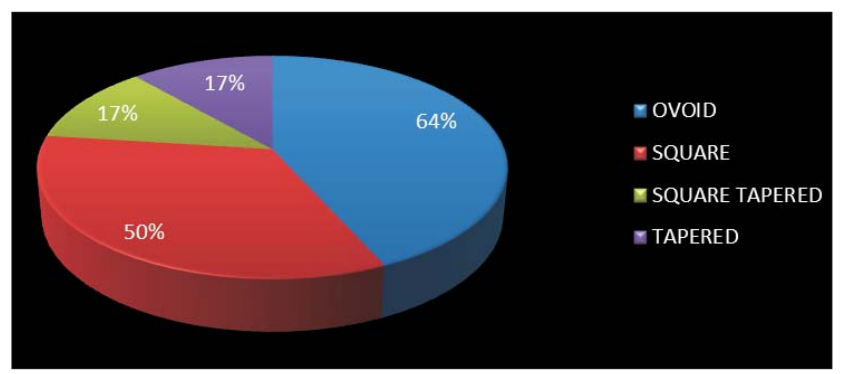

Graph I (a) : Percentage agreement between Tooth Form \& Face Form

correlating with ovoid face forms in about $64 \% .14$ square tooth forms are correlating with only 1 square, 5 ovoid, 6 square tapered, and 2 tapered face forms i.e. square tooth forms are correlating with square face forms in about $17 \% .23$ square-tapered tooth forms are correlating with 6 square tapered, 1 square, 10 tapered, and 6 ovoid face forms i.e. Square-tapered tooth forms are correlating with square tapered face forms in about 17\% (Graph. Ia).

Table 2 shows, correlation between tooth form and face form in males of Davangere population. 23 ovoid

Table 2: Correlation between tooth and face form in male

\begin{tabular}{|c|c|c|c|c|c|}
\hline $\begin{array}{c}\text { Tooth } \\
\text { Form }\end{array}$ & No. & $\begin{array}{c}\text { Ovoid } \\
\text { n }(\%)\end{array}$ & $\begin{array}{c}\text { Square } \\
\text { n (\%) }\end{array}$ & $\begin{array}{c}\text { Square- } \\
\text { Tapered }\end{array}$ & Tapered \\
\hline Ovoid & 23 & $\begin{array}{c}8 \\
(34.8 \%)\end{array}$ & - & $\begin{array}{c}12 \\
(52.2 \%)\end{array}$ & $\begin{array}{c}3 \\
(13.0 \%)\end{array}$ \\
\hline Square & 9 & $\begin{array}{c}1 \\
(11.1 \%)\end{array}$ & $\begin{array}{c}1 \\
(11.1 \%)\end{array}$ & $\begin{array}{c}6 \\
(66.7 \%)\end{array}$ & $\begin{array}{c}1 \\
(11.1 \%)\end{array}$ \\
\hline $\begin{array}{c}\text { Square- } \\
\text { Tapered }\end{array}$ & 11 & $\begin{array}{c}2 \\
(18.2 \%)\end{array}$ & $\begin{array}{c}1 \\
(9.1 \%)\end{array}$ & $\begin{array}{c}3 \\
(27.3 \%)\end{array}$ & $\begin{array}{c}5 \\
(45.5 \%)\end{array}$ \\
\hline Tapered & 7 & $\begin{array}{c}1 \\
(14.3 \%)\end{array}$ & - & $\begin{array}{c}3 \\
(28.6 \%)\end{array}$ & $\begin{array}{c}3 \\
(42.9 \%)\end{array}$ \\
\hline Total & 50 & $\begin{array}{c}12 \\
(24 \%)\end{array}$ & $\begin{array}{c}2 \\
(4 \%)\end{array}$ & $\begin{array}{c}24 \\
(48 \%)\end{array}$ & $\begin{array}{c}12 \\
(24 \%)\end{array}$ \\
\hline
\end{tabular}

$\mathrm{X}^{2}$ (Chi- Square test) $=8.99 \quad \mathrm{P}$ (Probability factor $)=0.44$ NS- Not Significant 
tooth forms are correlating with $8(34.8 \%)$ ovoid, 0 square, $12(52.2 \%)$ square-tapered, and $3(13.0 \%)$ tapered forms (Graph II). 9 square tooth forms are correlating with only 1 (11.1\%) square, 1 (11.1\%) ovoid, $6(66.75 \%)$ square tapered, and 1 (11.1\%) tapered face forms.

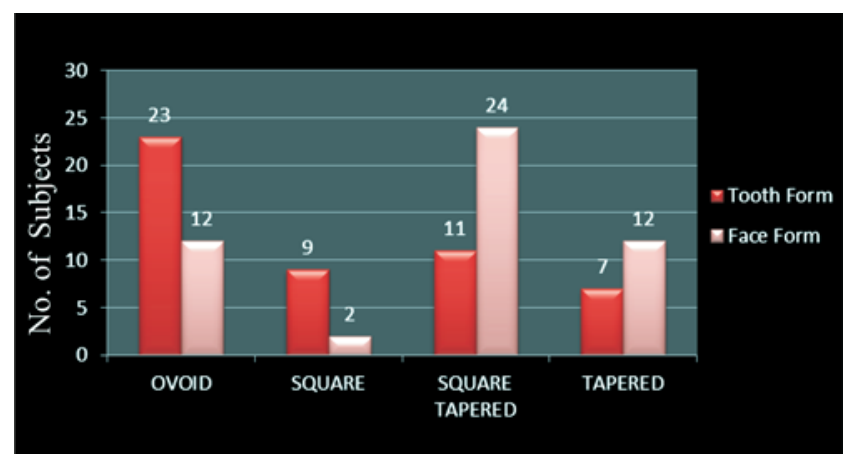

Graph II: Relation between Tooth Form \& Face Form in Male Population of Davangere

11 square-tapered tooth forms are correlating with 3 (27.3\%) square-tapered, 2 (18.2\%) ovoid, 1 (9.1\%) square, and $5(45.5 \%)$ tapered face forms. 7 tapered tooth forms are correlating with $3(42.9 \%)$ tapered, 3 $(28.6 \%)$ square-tapered, 0 square, and $1(14.3 \%)$ ovoid face forms.

In total, only $30 \%$ of the male population of Davangere is having maxillary central incisor tooth form correlating with face form.

Table 3 shows, correlation between maxillary central incisor tooth form and face form in females of Davengere population(Graph. III). 30 ovoid maxillary

Table 3: Correlation between tooth and face form in female

\begin{tabular}{|c|c|c|c|c|c|}
\hline $\begin{array}{c}\text { Tooth } \\
\text { Form }\end{array}$ & No. & $\begin{array}{c}\text { Ovoid } \\
\text { n (\%) }\end{array}$ & $\begin{array}{c}\text { Square } \\
\text { n (\%) }\end{array}$ & $\begin{array}{c}\text { Square- } \\
\text { Tapered }\end{array}$ & Tapered \\
\hline Ovoid & 30 & $\begin{array}{c}17 \\
(56.7 \%)\end{array}$ & - & $\begin{array}{c}9 \\
(30 \%)\end{array}$ & $\begin{array}{c}4 \\
(13.3 \%)\end{array}$ \\
\hline Square & 05 & $\begin{array}{c}4 \\
(80 \%)\end{array}$ & - & - & $\begin{array}{c}1 \\
(20 \%)\end{array}$ \\
\hline $\begin{array}{c}\text { Square- } \\
\text { Tapered }\end{array}$ & 12 & $\begin{array}{c}4 \\
(33.3 \%)\end{array}$ & - & 3 & $\begin{array}{c}5 \\
(25 \%)\end{array}$ \\
\hline Tapered & 3 & $\begin{array}{c}2 \\
(66.7 \%)\end{array}$ & - & - & $1.7 \%)$ \\
\hline Total & 50 & $\begin{array}{c}27 \\
(54 \%)\end{array}$ & - & $\begin{array}{c}12 \\
(24 \%)\end{array}$ & $\begin{array}{c}11 \\
(22 \%)\end{array}$ \\
\hline
\end{tabular}

$\mathrm{X}^{2}$ (Chi-Square test) $=7.39$

$\mathrm{P}$ (Probability Factor $)=0.89$

NS - Not Significant

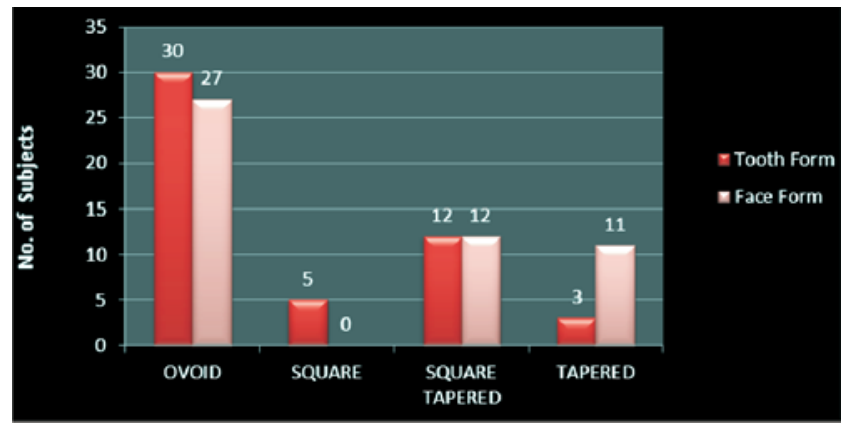

Graph III: Relation between Tooth Form \& Face Form in Female Population of Davangere

central incisor tooth forms are correlating with 17 (56.7\%) ovoid, 0 square, 9 (30.0\%) square-tapered, and $4(13.3 \%)$ tapered face forms. 5 square maxillary central incisor tooth forms are correlating with 0 square, 0 square -tapered, $1(20 \%)$, and $4(33.3 \%)$ ovoid face form. 12 square-tapered maxillary central incisor tooth forms are correlating with 3 (25\%) squaretapered, 0 square, $4(33,3 \%)$ ovoid, and 5 (41.3\%) tapered face-forms. 3 tapered maxillary central incisor tooth forms are correlating with $1(33.3 \%)$ tapered, 0 squares, 0 square-tapered and $2(66.7 \%)$ ovoid face forms.

In total, $42 \%$ of female population of Davangere is having maxillary central incisor tooth form correlating with face form.

Table 4 shows the predominant tooth form in males and females of Davangere population(Graph IV). Results shows, ovoid tooth form (46\%) predominant in males followed by square-tapered

Table 4: Predominant tooth form in male and female

\begin{tabular}{|c|c|c|c|c|c|}
\hline Sex & No. & $\begin{array}{c}\text { Ovoid } \\
\text { n (\%) }\end{array}$ & $\begin{array}{c}\text { Square } \\
\text { n (\%) }\end{array}$ & $\begin{array}{c}\text { Square- } \\
\text { Tapered } \\
\text { n (\%) }\end{array}$ & $\begin{array}{c}\text { Tapered } \\
\mathbf{n}(\%)\end{array}$ \\
\hline Males & 50 & 23 & 9 & 11 & 7 \\
$(46 \%)$ & $(18 \%)$ & $(22 \%)$ & $(14 \%)$ \\
\hline Females & 50 & 30 & 5 & 12 & 3 \\
$(60 \%)$ & $(10 \%)$ & $(24 \%)$ & $(6 \%)$ \\
\hline Total & 100 & 53 & 14 & 23 & 10 \\
\hline
\end{tabular}

$\mathrm{X}^{2}$ (Chi-Square test) $=3.71$

$\mathrm{P}($ Probability factor $)=0.29$

NS - Not Significant

$(22 \%)$, square (18\%), and tapered tooth forms (14\%). Ovoid tooth form $(60 \%)$ predominant in females followed by square-tapered (24\%), square $(0 \%)$, and tapered face forms $(6 \%)$. 


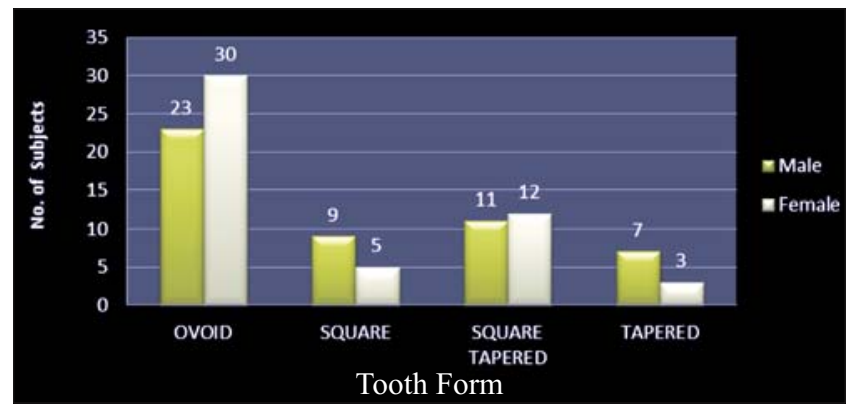

Graph IV: Predominant Tooth Form in Male \& Female Population of Davangere

Table 5 shows predominant face-form in males and females (Graph V). Results show square-tapered faceform $(48 \%)$ predominant in males followed by ovoid $(24 \%)$, tapered $(24 \%)$, and square $(4 \%)$. Ovoid faceform $(54 \%)$ predominant in females followed by square-tapered (24\%), tapered (22\%) and square faceforms $(0 \%)$.

Table 5: Predominant face form in male and female

\begin{tabular}{|c|c|c|c|c|c|}
\hline Sex & No. & $\begin{array}{l}\text { Ovoid } \\
\text { n (\%) }\end{array}$ & $\begin{array}{c}\text { Square } \\
\text { n (\%) }\end{array}$ & $\begin{array}{c}\text { Square-Tapered } \\
\text { n }(\%)\end{array}$ & $\begin{array}{c}\text { Tapered } \\
\text { n }(\%) \\
\end{array}$ \\
\hline Males & 50 & $\begin{array}{c}12 \\
(24 \%)\end{array}$ & $\begin{array}{c}2 \\
(4 \%)\end{array}$ & $\begin{array}{c}24 \\
(48 \%)\end{array}$ & $\begin{array}{c}12 \\
(24 \%)\end{array}$ \\
\hline Females & 50 & $\begin{array}{c}27 \\
(54 \%)\end{array}$ & 0 & $\begin{array}{c}12 \\
(24 \%)\end{array}$ & $\begin{array}{c}11 \\
(22 \%)\end{array}$ \\
\hline Total & 100 & 39 & 2 & 36 & 23 \\
\hline $\begin{array}{l}X^{2} \text { (Chi-S } \\
\text { P (Probab } \\
\text { Sig. = Sig }\end{array}$ & ility & $\begin{array}{l}\text { Test) } \\
\text { Factor) }\end{array}$ & $\begin{array}{l}=11.8 \\
=<0.01\end{array}$ & & \\
\hline
\end{tabular}

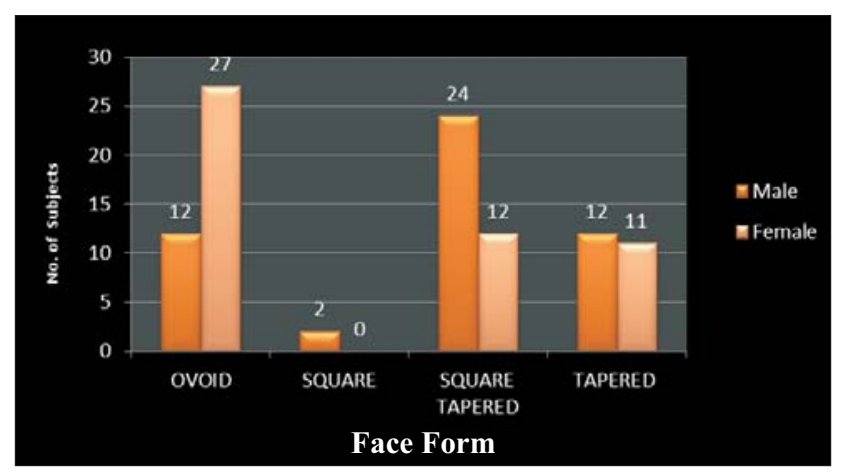

Graph V: Predominant Face Form in Male \& Female Population of Davangere

\section{DISCUSSION}

The concept of tooth selection in complete denture prosthodontics has changed from basic human temperaments and typal or geometric shapes to selecting and modifying the teeth according to the
Philosophy of creating the effects of sex, personality and age. Since, most of the time an edentulous patient reports for complete denture treatment without any definitive information about his lost natural tooth, it has become necessary to look for some craniofacial landmarks and derive information on the size of the natural teeth through biometry, such that the anterior teeth are in a pleasing proportion to the face and the size of the natural teeth do not exhibit extreme characteristics, but harmonize with the face and growth profile of the patient. ${ }^{6}$

Correlation with teeth and face forms has long been recognized. W.R. Hall ${ }^{7}$ in 1887 projected the "Typal form concept" based on the tooth's labial surface curvatures, outline form and neck width. Accordingly, he classified face form as ovoid, tapering and square.

Heartwell $^{8}$ said that by using tooth indicator, patients face forms can be found out. It is best observed by noting the particular characteristics of each form as it appears in comparison with the vertical lines of the indication. In the square form, the side of the face will be in comparison with the vertical lines of the indicator. In the square tapering, form the upper third of the lower two third will taper inward. In tapering faces, the sides of the forehead to the angel of the jaw will taper inward diagonal. Ovoid faces will be best determined by the examination of the curved outline of the face against the straight vertical lines of the tooth indicator.

In the present study, face form and tooth form of 50 female and 50 male population of Davangere were evaluated, clinically correlated and it was found that female subjects had a higher correlation ( $42 \%$ ) between the face form and inverted maxillary central incisor tooth form as compared to the male subjects $(30 \%)$. These findings were in accordance with those of Lindemann H.B., Knauer C. and Pfeiffer P. In that they conducted a study to determine whether a relationship exists between maxillary central incisor and face shape. A standardized digital photographic procedure was used to record frontal views of each subject's face and of the maxillary central incisors. They end up with the conclusion that, female and higher significant correlation values between maxillary central incisor 
and face form, compared to that of male patients.

In the present study, face form and maxillary central incisor tooth were evaluated and correlated clinically. Face form was made using "Trubyte tooth indicator". Tooth form was evaluated using mesiodistal dimensions from the cast. Results of the study revealed insignificant correlation between the face form and maxillary central incisor tooth form. These findings were in accordance with the findings of Sellen P., Jagger D., Harrison $\mathrm{A}^{10}$ who evaluated the interrelationship between five aesthetic factors.

$>$ The form of the face

$>$ Tooth

$>$ Arch

$>$ Maxillary anterior tooth arrangement

$>$ Palatal contour

An assessment was made to determine if correlation was sufficient to recommend their use as reliable aesthetic factors for the selection of suitable tooth moulds for edentulous and partially edentulous patients. A computer programme was developed incorporating image of the factors taken from 50 Caucasian adults aged 20 to 31 years. Assessment of correlation was made by outline superimposition and classification. They end up with the conclusion that there was insufficient correlation to support Nelson's "Aesthetic Triangle", or "Williams" face/tooth form theory.

In the present study, an effort was made to determine the predominant tooth form in female subject. Result from the study obtained reveal, ovoid tooth form predominant for female subjects. These finds were in accordance with the findings of Marunick MT, Chanberlain BB, Robinson CA. ${ }^{19}$ They conducted a study to evaluate whether the lay public perceives anterior teeth selected by William's typal matching method as aesthetically pleasing. The study was tested by layman responding to question about photographs of 3 edentulous male and three edentulous female patients, they found out that, overall ovoid teeth are preferred of females.

In the present study, an attempt was made to correlate the face form and inverted maxillary central incisor tooth in 50 male and 50 female population of
Davangere in order to check the validity of the theory of "Williams' that the tooth shape should correspond to the inverted facial shape. Results, thus obtained were showing insignificant correlation. These finds are in accordance with Stefan Wolfart, Helger Menzel, Mathias Kem. ${ }^{12}$ In 2004 examined whether there exists a gender dependent correlation between the inverted face shape and that of the upper central incisor. They end up with the conclusion that, the theory, the tooth shape should correspond to the inverted facial shape could not therefore be confirmed.

Based on the above results, the dentist can clinically arrive at certain conclusion during the diagnostic phase. When any face form is evaluated clinically, we should not end up with the selection of maxillary central incisor of the same form. The other factors should be evaluated along with the face form in order to achieve aesthetically pleasing result.

As no universally accepted method for selection of teeth has yet been established, dentists must seek guidance from a variety of techniques using their clinical experience and esthetic sense to attain what is hoped will be an acceptable result.

\section{CONCLUSION}

From the study it is concluded that:

No significant correlation existed between face form and inverted maxillary central incisor tooth form in both male and female population.

$>$ Among male and female population, females exhibit greater correlation between face form and inverted tooth form but that correlation is not sufficient to serve as a guide for selection of anterior teeth.

$>$ The predominant tooth form in male and female population is ovoid.

$>$ The predominant face form in males is squaretapered.

$>$ The predominant face form in females is ovoid.

Based on the above results, the dentist can clinically arrive at certain conclusion during the 
diagnostic phase.

As esthetic dentures do not occur automatically, for such is the product of an artist - a denture artist.

So, prospective denture artists should realize that an increased sensibility to, and a high evaluating skill of, the physical esthetic qualities in the edentulous face is acquired by much observing of human dentofacial physical beauty values and by the dint of trial and error in creating the desired results by denture qualities. Reading books on art or aesthetics and attending lectures are helpful, but the artist must learn to apply beauty fundamentals and develop his aesthetic tastes.

\section{SUMMARY}

The present study was conducted to determine the correlation between face form and maxillary central incisor tooth form in male and female population of Davangere.

The face form was divided into 4 groups viz., tapering, ovoid, square, square tapering. The face form was determined clinically using a Trubyte tooth indicator.

The tooth form was determined clinically by measuring the mesiodistal width of cervical one-third, middle one-third, and incisal one-third of maxillary central incisor from the contact point.

The results obtained clinically were correlated and tabulated. A qualitative analysis was done to know the concordance clinically.

CONFLICT OF INTEREST- None identified

\section{REFERENCES}

1) Young HA. Denture Esthetics. Journal of Prosthetic Dentistry 1956; 6(6): 749-752.
2) Dayton Dunbar Krajicek. Guides for natural facial appearance as related to complete denture construction. Journal of Prosthetic Dentistry 1969; 21 (6) : 654-2.

3) Sellon PN, Phil B, Jagger DC, Harrison A. Computergenerated study of the correlation between tooth, face, arch forms, and palatal contour. Journal of Prosthetic Dentistry $1998 ; 80: 163-168$.

4) Ryle A. Bell. The geometric theory of selection of artificial teeth : Is it valid? Journal of American Dental Association 1978; 97: 637-40.

5) Mavroshoufis F., Ritchie GM. The face form as a guide for the selection of maxillary central incisors. Journal of Prosthetic Dentistry 1980; 43 (5):501-5.

6) Lombardi Richard E. The Principle of visual perception and their clinical application to denture esthetics. Journal of Denistry $1973 ; 29(4): 358-82$.

7) Young HA. Selecting the anterior tooth mold. Journal of Prosthetic Dentistry 1954; 6(6): 750-759.

8) Heartwell Charles M, Rahn Arthur. Syllabus of complete dentures Philadephia, 4th Edition, Lea and Febiger 1986; 31319.

9) Lindemann HB, Knauer C, Pfeiffer P. Morphometric relationships between tooth and face shapes. Journal of Oral rehabilitation $2004 ; 31(10): 972$.

10) Sellon P, Jagger D, Harrison A. The correlation between selected factors which influence dental aesthetics. Primary Dental Care 1998 ; 5 (2): 55-60.

11) Marunick MT, Chamberlain BB, Robinson CA. Denture aesthetics : an evaluation of laymen's preferences. Journal of Oral Rehabilitation $1983 ; 10(5)$ : 399-06.

12) Stefan Wolfart, Holger Menzen, Matthias Kem. Inability to relate tooth forms to face shape and gender. European Journal of Oral Sciences $2004 ; 112(6): 471$.

Source of Support: Nil, Conflict of Interest: None Declared 